\title{
Expression and Prognostic Impact of VEGF, CD31 and $\alpha$ SMA in Resected Primary Lung Cancers
}

\author{
KATSUO USUDA $^{1}$, SYUN IWAI $^{1}$, AIKA FUNASAKI ${ }^{1}$, ATSUSHI SEKIMURA $^{1}$, \\ NOZOMU MOTONO ${ }^{1}$, YOSHIMITI UEDA ${ }^{2}$, MIYAKO SHIMAZAKI ${ }^{2}$ and HIDETAKA URAMOTO ${ }^{1}$ \\ ${ }^{1}$ Department of Thoracic Surgery, Kanazawa Medical University, Ishikawa, Japan; \\ ${ }^{2}$ Department of Pathophysiological and Experimental Pathology, Kanazawa Medical University, Ishikawa, Japan
}

\begin{abstract}
Background/Aim: One of the most important factors concerning cancer growth is angiogenesis. The purpose of this study was to clarify the relationship of maturation of tumor vessels and prognosis of lung cancer. Materials and Methods: Immunohistochemical stainings of 125 lung cancers for VEGF, CD31 and $\alpha$-smooth muscle actin ( $\alpha S M A)$ were scored by multiplying the intensity and the frequency from 0 to 12. Results: Adenocarcinomas showed significantly higher staining scores of both VEGF and $\alpha S M A$ than squamous cell carcinomas did. In 42 cases of high CD31 score, five-year survival rate (87\%) of patients with lung cancer showing mature tumor vessels was significantly better than that (69\%) of patients with immature tumor vessels. Conclusion: Not the number of tumor vessels but their maturation may be a prognostic factor of patients with lung cancer. VEGF may not only stimulate proliferation of endothelial cells but also their maturation in differentiated lung cancers.
\end{abstract}

Lung cancer is one of the most common leading causes of cancer mortality. One of the most important factors concerning cancer growth/progression is tumor angiogenesis. The angiogenesis is regulated by various growth factors. Vascular endothelial growth factor (VEGF) was demonstrated to be playing the central role in lung cancer (1). Bevacizumab (Avastin), which is a monoclonal antibody to VEGF, intercepts VEGF signals inducing tumor angiogenesis, and has been widely used for treatment of nonsquamous lung cancer. Angiogenesis is generally evaluated by counting the number of capillaries, by means of

Correspondence to: Katsuo Usuda, MD, Department of Thoracic Surgery, Kanazawa Medical University. 1-1 Daigaku, Uchinada, Ishikawa, 920-0293, Japan. Tel: +81 762862211, Fax: +81 762861207, e-mail: usuda@kanazawa-med.ac.jp

Key Words: Lung cancer, VEGF, tumor vessels, maturation, prognostic factor. immunohistochemistry using specific antibodies such as anti CD31 antibody, in the tumor tissues. Previous studies on the prognostic value of angiogenesis in cancer are still controversial: Although VEGF expression was reported to be independent predictive factor of poorer prognosis $(2,3)$, Weng WC et al. (4) reported that positive VEGF expression of neuroblastomas was found to correlate well with histological grade of differentiation and predicted a favorable prognosis showing its adverse impact on the prognosis.

Endothelial cells are stained by CD31, as a marker for endothelial cells, and pericytes/smooth muscle cells are stained by $\alpha \mathrm{SMA}$, as a marker for pericytes/smooth muscle cells. Mature blood vessels consist of endothelial cells and pericytes/smooth muscle cells, stabilizing vascular structures and controlling their permeability. A mature blood vessel would be presented as a vessel of CD31(+) and $\alpha \mathrm{SMA}(+)$; an immature blood vessel would be presented as a vessel of CD31(+) and $\alpha$ SMA (-). Solid tumors require more blood vessels for growth than normal tissues. Being compared with normal blood vessels, tumor vessels are immature, deprived of pericytes, and known to have loose adhesion among vascular endothelium cells.

The purpose of this study was to clarify the influence of maturity of tumor vessels as well as density of tumor blood vessels and the expression of VEGF in tumor tissues on postoperative survival of patients with lung cancer. We demonstrate favorable prognostic impact of the maturity of tumor vessels in differentiated lung cancers with increased angiogenesis, proposing an alternative role of VEGF as a maturation-inducer in vivo.

\section{Materials and Methods}

Eligibility. The study protocol of examining resected material of lung cancer was approved by the ethical committee of Kanazawa Medical University (Approval Number: No. 15-28). Informed consent for examining resected material of lung cancer were obtained from each patient when surgeons explained details of the operation.

Patients. Tumor samples were obtained from 125 patients who underwent pulmonary resection for lung cancer at Kanazawa 
Medical University Hospital from July 2001 to July 2010 (Table I). Overall, 80 patients were male and 45 were female. Their mean age was 66.1 years old (range $=31-81$ years old). There were 101 adenocarcinomas, 21 squamous cell carcinomas, and 3 small cell carcinomas. There were 4 pneumonectomies, 2 bilobctomies, 108 lobectomies, 2 segmentectomies and 9 wedge resections. TNM classification and the lymph node stations of the lung cancer were classified according to the definition of UICC 8 (5). There were 44 pathological T1a (pT1a) carcinomas, 33 pT1b carcinomas, 32 pT2a carcinomas, 3 pT2b carcinomas, 12 pT3 carcinomas and 1 pT4 carcinoma. There were 96 pathological N0 (pN0) carcinomas, 16 pN1 carcinomas and 13 pN2 carcinomas. There were 69 pathological Stage IA (pStage IA) carcinomas, 22 pStage IB carcinomas, 9 pStageIIA carcinomas, 5 pStage IIB carcinomas, 14 pStage IIIA carcinomas, 1 pStage IIIB carcinoma and 5 pStage IV carcinomas. For cell differentiation, there were 64 well differentiated carcinomas, 28 moderately differentiated carcinomas, 30 poorly differentiated carcinomas and 3 undifferentiated carcinomas.

Immunohistochemistry and scoring. Immunostaining was performed with spiral tissue microarray technology (6). Paraffin blocks of lung cancer were heated around $40^{\circ} \mathrm{C}$ on the surface, and $120 \mu \mathrm{m}$-thick sections were cut with a microtome. The tissue sections were manually rolled up into tissue reels. Each tissue reel was then cut into $3 \mathrm{~mm}$-tall subcylindrical reel. Each subcylindrical reel was vertically embedded into plastic tissue-holding-cassette with 26 holes of $3.3 \mathrm{~mm}$ diameter (Azumaya Co. Ltd., Tokyo, Japan). Melted paraffin was poured into the cassette to re-embed the reeled tissue followed by cooling down. Lastly, the Spiral Array block was sectioned at $5 \mu \mathrm{m}$.

Immunohistochemical staining for VEGF, CD31 or $\alpha$ SMA was performed with the streptavidin-biotin method (Figure 1). In brief, sections were dewaxed and microwave treated at $121^{\circ} \mathrm{C}(500 \mathrm{~W})$ for $10 \mathrm{~min}$ in $10 \mathrm{mM}$ sodium citrate $(\mathrm{pH} 6.0)$. Endogenous peroxidase was blocked by incubation in $3 \%$ hydrogen peroxide in methanol for $5 \mathrm{~min}$ at room temperature. The sections were incubated with each primary antibody at $4^{\circ} \mathrm{C}$ for $16 \mathrm{~h}$. The primary antibodies used were: a mouse monoclonal antibody against VEGF protein (ab68334, Abcam, Cambridge, UK, $1.0 \mu \mathrm{g} / \mathrm{ml}$ ); a mouse monoclonal antibody against CD31 protein (NCL-CD31-1A10, Novocastra, Newcastle Upon Tyne, UK, $20 \mu \mathrm{g} / \mathrm{ml}$ ); a mouse monoclonal antibody against $\alpha$ SMA protein (HHF35, Dako, Troy, MI, USA $1.0 \mu \mathrm{g} / \mathrm{ml}$ ). After washing three times with trisphosphate buffered saline (TBS), sections were incubated with secondary antibody (biotinylated goat antirabbit immunoglobulin G) (Histofine SAB-PO kit, Nichirei, Tokyo, Japan) for $10 \mathrm{~min}$. They were then washed three times with TBS, treated with streptavidinperoxidase reagent (Histofine, Nichirei, Tokyo, Japan) for $10 \mathrm{~min}$, and then washed with TBS three times again. Finally, specimens were incubated in diaminobenzidine (Nichirei) for $5 \mathrm{~min}$, followed by haematoxylin counterstaining. Negative controls for each tissue section were prepared by omitting the primary antibody. Positive controls for each tissue section were prepared by macrophages for VEGF, vessel walls for CD31 and fibroblasts for aSMA. Two experienced investigators (YU, MS) examined the slides in a 200x magnified field without knowledge of the corresponding clinicopathological data. Staining intensity and frequency of VEGF, CD31 or aSMA in the lung cancer cells were assessed with a modified Saijo's method (7). The moderate staining was
Table I. Patients characteristics.

No.

\begin{tabular}{lr}
\hline Gender & \\
Male & 80 \\
Female & 45 \\
Cell type & \\
Adenoca. & 101 \\
Squamous cell ca. & 21 \\
Small cell ca. & 3 \\
pT factor & \\
pT1a & 44 \\
pT1b & 33 \\
pT2a & 32 \\
pT2b & 3 \\
pT3 & 12 \\
pT4 & 1 \\
pN factor & \\
pN0 & 96 \\
pN1 & 16 \\
pN2 & 13 \\
pStage & \\
pIA & 69 \\
pIB & 22 \\
pIIA & 9 \\
pIIB & 5 \\
pIIIA & 14 \\
pIIIB & 1 \\
pIV & 5 \\
Cell differentiation & 3 \\
Well & \\
Moderately & 64 \\
Poorly & 28 \\
Undifferentiated & 30 \\
\hline & \\
& \\
&
\end{tabular}

comparable to the staining intensity observed for positive control sections. A mature blood vessel would be presented as a vessel of CD31(+) and aSMA (+), otherwise an immature blood vessel would be presented as a vessel of CD31(+) and $\alpha$ SMA (-). The staining intensity of VEGF, CD31 or $\alpha$ SMA in lung cancer cells were classified and numbered into 4 categories as follows: none $=0$; weak $=1$; moderate $=2$; and strong $=3$. The staining frequency $(\%)$ of positively stained cells of VEGF, CD31 or $\alpha$ SMA in total lung cancer cells in 4 representative field, were classified and numbered into 5 categories as follows: $0 \%=0 ; 1-10 \%=1 ; 11-25 \%=2 ; 26-$ $50 \%=3 ; 51-100 \%=4$. To obtain semiquantitative values for VEGF, C D31 or $\alpha$ SMA antigen per tissue, the staining score of each VEGF, CD31 or $\alpha$ SMA antigen was calculated by multiplying the staining intensity score by the staining frequency score (range $=0$ 12). The staining scores of each VEGF, CD31 or $\alpha$ SMA antigen were divided into a high score group and a low score group by the mean score. Survival rates were compared by the staining scores of each VEGF, CD31 or $\alpha$ SMA antigen.

Ethical approval. The study protocol of examining resected material of lung cancer was approved by the ethical committee of Kanazawa Medical University (Approval Number: No. 15-28). 


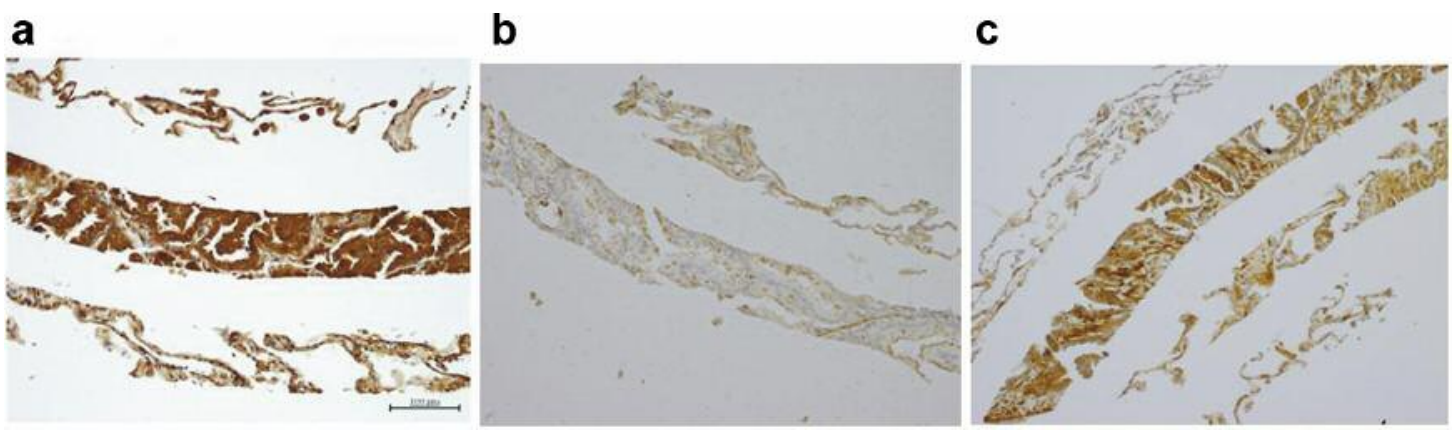

Figure 1. Immunohistochemical staining for a section of the Spiral Array block $\times 200 . a$ : VEGF, b: CD31, c: $\alpha$ SMA.

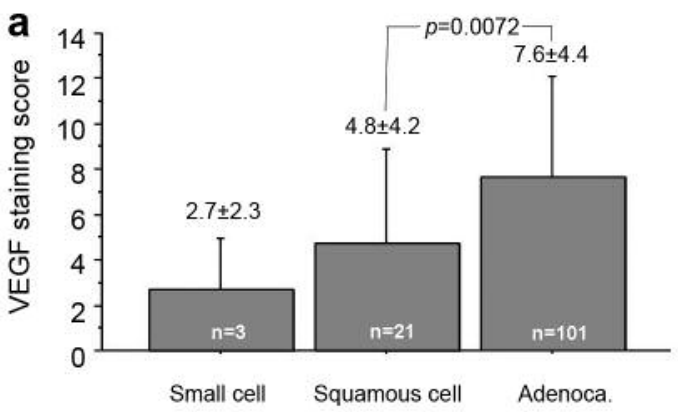

ca. ca.

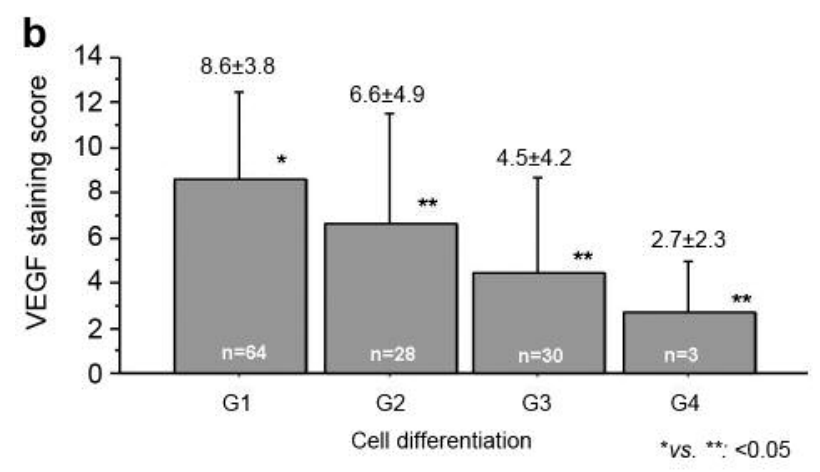

Figure 2. VEGF score according to cell types (a) or cell differentiation (b). VEGF score according G1: Well differentiation; G2: moderately differentiation; G3: poor differentiation; G4: undifferentiation.

Statistical analysis. The data are expressed as the mean \pm standard deviation. A two-tailed Student $t$ test was used for comparison of the mean values. The Kaplan-Meier method was used to calculate the survival rate with a $95 \%$ confidence interval (CI), and the logrank tests were used to compare the survival curves. For the statistical analyses, the computer software program StatView for Windows was used (Version 5.0; SAS Institute Inc. Cary, NC, USA). A $p$-value $<0.05$ was considered statistically significant.
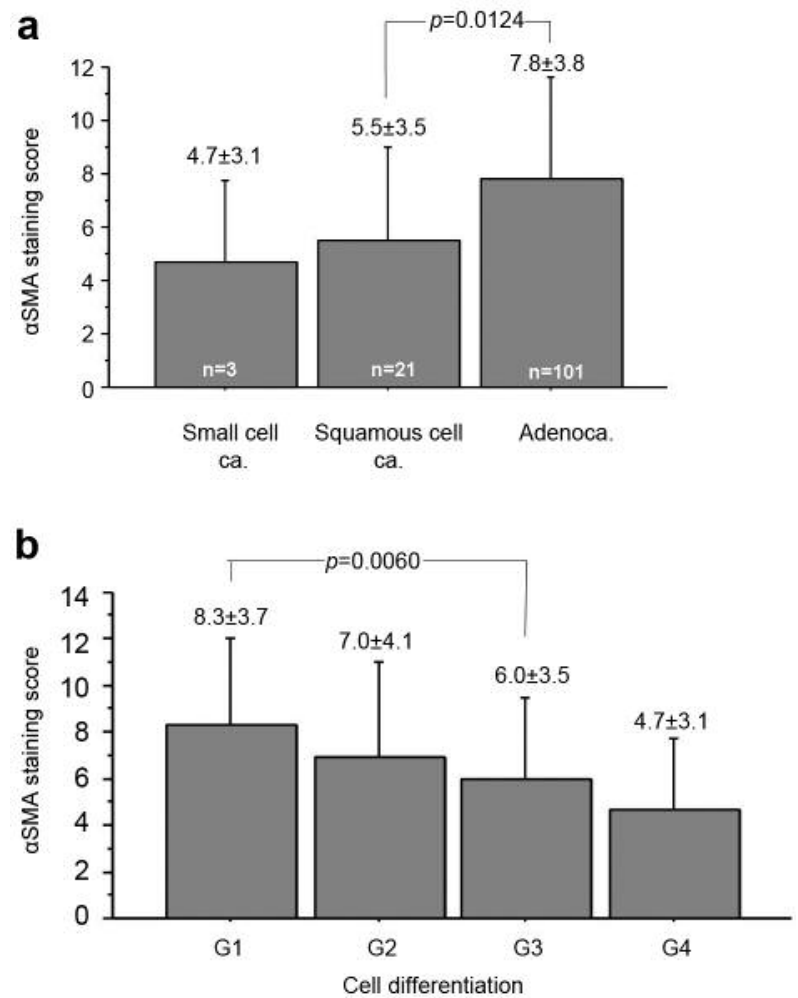

Figure 3. $\alpha S M A$ scores according to cell types (a) and cell differentiation (b). G1: Well differentiation; G2: moderately differentiation; G3: poor differentiation; G4: undifferentiation.

\section{Results}

Staining frequencies (\%) of VEGF were 50.3 \pm 30.6 in adenocarcinomas, $27.1 \pm 25.9$ in squamous cell carcinomas, and $10 \pm 10$ in small cell carcinomas, the staining frequency of adenocarcinomas was significantly higher than that of squamous cell carcinomas or small cell carcinomas. VEGF 

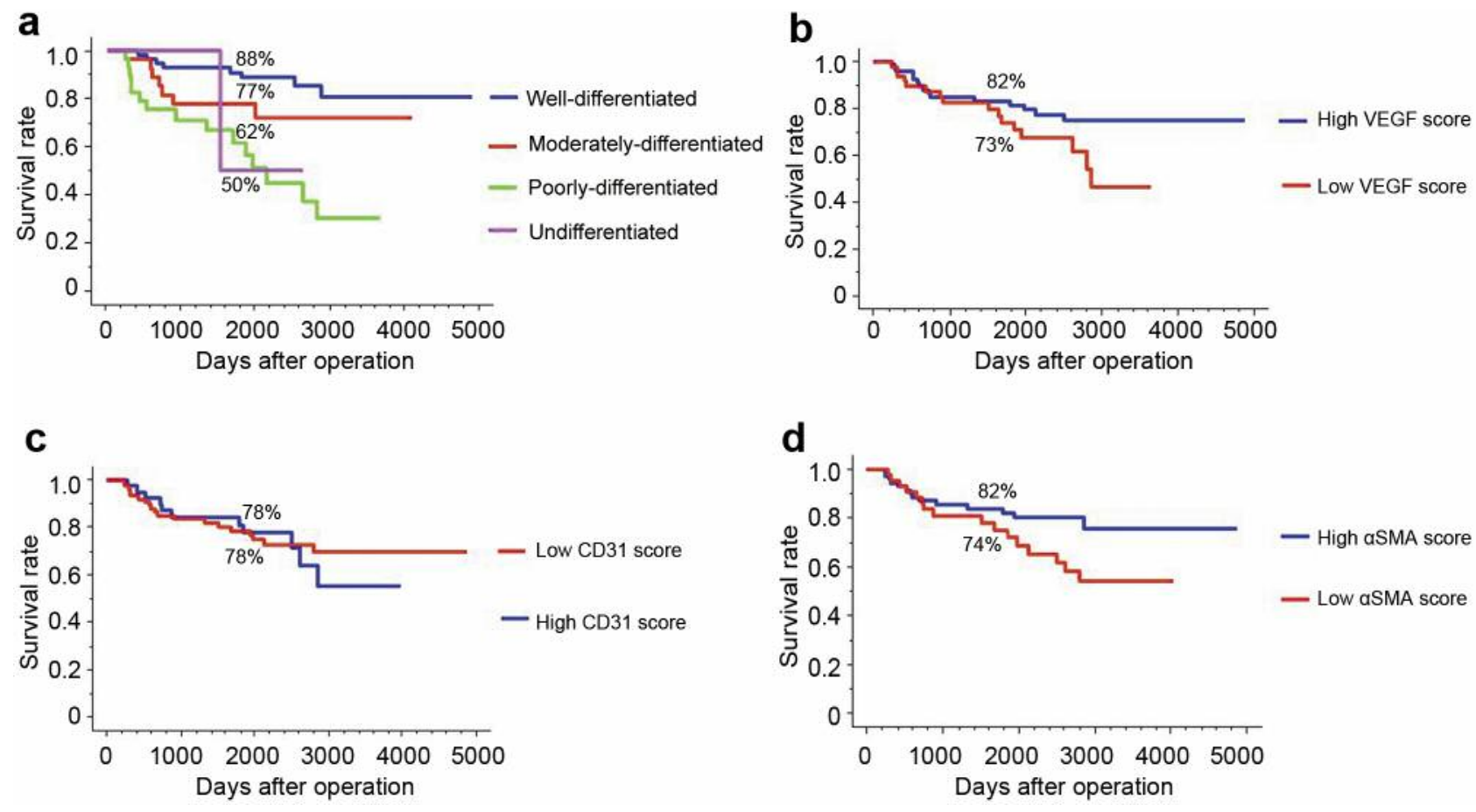

Figure 4. Comparisons of survival curves by cell differentiation, VEGF, CD31, and $\alpha$ SMA staining scores. a. Survival curves by cell differentiation . $p=0.0002$. $b$. Survival curves by VEGF staining score. $p=0.094$. $c$. Survival curves by CD31 staining score. $p=0.764 d$. Survival curves by $\alpha$ SMA staining score $p=0.094$.

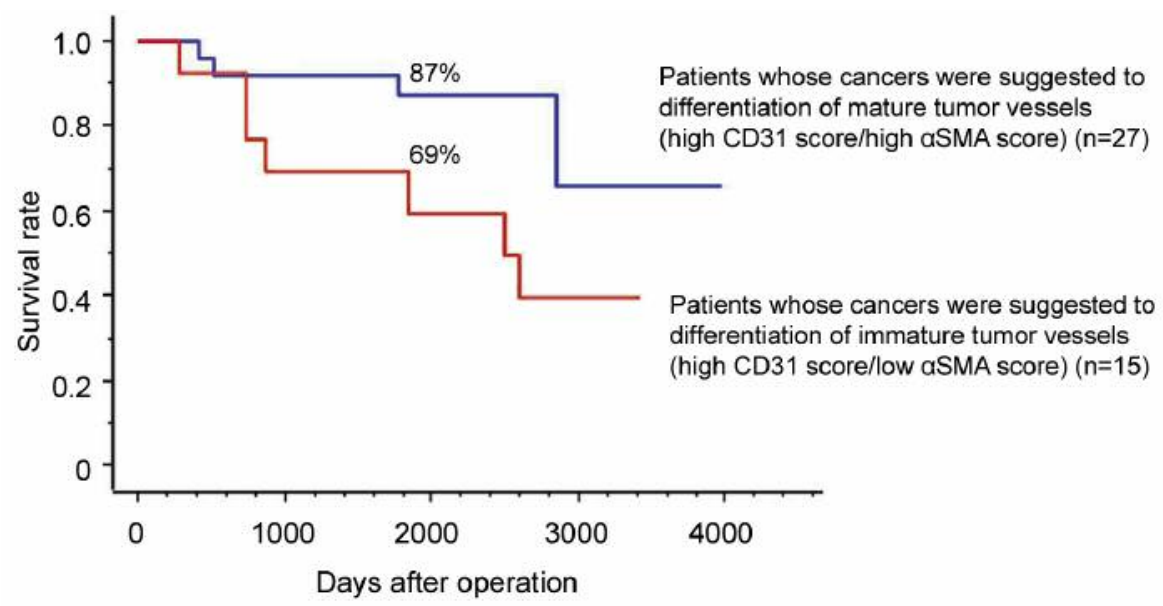

Figure 5. Comparison of survival rates between patients whose cancers were suggested to differentiation of mature tumor vessels and patients whose cancers were suggested to differentiation of immature tumor vessels. $p=0.048$.

staining scores were $7.6 \pm 4.4$ in adenocarcinomas, $4.8 \pm 4.2$ in squamous cell carcinomas, and $2.7 \pm 2.3$ in small cell carcinomas. VEGF staining scores of adenocarcinomas were significantly higher than that of squamous cell carcinomas (Figure 2a). VEGF staining scores were $8.6 \pm 3.8$ in welldifferentiated lung cancers, $6.6 \pm 4.9$ in moderatelydifferentiated lung cancers, $4.5 \pm 4.2$ in poorly-differentiated lung cancers, and $2.7 \pm 2.3$ in undifferentiated lung cancer. VEGF staining scores of well-differentiated lung cancers were significantly higher than that of moderately-differentiated, poorly-differentiated or undifferentiated lung cancers (Figure 2b). $\alpha$ SMA staining scores were $7.8 \pm 3.8$ in adenocarcinomas, $5.5 \pm 3.5$ in squamous cell carcinomas, and $4.7 \pm 3.1$ in small cell carcinomas, $\alpha$ SMA staining scores of adenocarcinomas 
were significantly higher than that of squamous cell carcinomas $(p=0.0124)$ (Figure 3a). $\alpha$ SMA staining scores were $8.3 \pm 3.7$ in well-differentiated lung cancers, $7.0 \pm 4.1$ in moderately-differentiated lung cancers, $6.0 \pm 3.5$ in poorlydifferentiated lung cancers, and $4.7 \pm 3.1$ in undifferentiated lung cancer. $\alpha$ SMA staining scores of well-differentiated lung cancers were significantly higher than that of poorly differentiated lung cancers $(p=0.0060)$ (Figure 3b). CD31 staining scores were $4.8 \pm 2.8$ in adenocarcinomas, $5.0 \pm 2.1$ in squamous cell carcinomas, and $4.0 \pm 0$ in small cell carcinomas. CD31 staining scores were 5.3 \pm 3.0 in well-differentiated lung cancers, $4.9 \pm 2.5$ in moderately-differentiated lung cancers, $4.1 \pm 1.9$ in poorly-differentiated lung cancers, and $4.0 \pm 0$ in undifferentiated lung cancer. There were no significant correlations among VEGF staining scores, CD31 staining scores and $\alpha$ SMA staining scores (coefficients of correlation (r) is equal to or less than 0.2 among them).

Concerning survival curves, there were significant differences among survival rates by cell differentiations $(p=0.0002)$ (Figure $4 a)$. Five-year survival rate $(82 \%)$ of patients with high VEGF score $(n=74)$ tended to be better than that $(73 \%)$ of patients with low VEGF score $(n=51)$, but there was no significant difference $(p=0.094)$ (Figure $4 b)$. Five-year survival rate $(78 \%)$ of patients with low CD31 score $(n=83)$ was same as that $(78 \%)$ of patients with high CD31 score $(n=42)$ (Figure 4c). Five-year survival rate $(82 \%)$ of patients with high $\alpha$ SMA score $(n=74)$ tended to be better than that $(74 \%)$ of patients with low $\alpha$ SMA score $(\mathrm{n}=51)$, but there were no significant differences $(p=0.094)$ (Figure 4d). Although mature vessels of cancer were thought to show immunostaining of high CD31 score/high $\alpha$ SMA score, and immature vessels of cancer immunostaining of high CD31 score/low aSMA score, the analysis could not be performed in individual vessels. Patients were classified into 4 groups according to CD31 staining score (high or low score) and $\alpha$ SMA staining score (high or low score). Fiveyear survival rate $(87 \%)$ of 27 patients whose cancers were believed to have differentiated into mature vessels (high CD31 score/high $\alpha$ SMA score) was significantly better than $(69 \%)$ that of 15 patients whose cancers were believed to have differentiated into immature vessels (high CD31 score/low $\alpha$ SMA score) $(p=0.048)$ (Figure 5).

\section{Discussion}

Vascularization plays an important role in the growth of neoplasm. VEGF is a key factor of vascularization and is necessary for the growth and metastasis of neoplasm. Once VEGF binds to the VEGF receptor in the cell surface, cell proliferation, vascularization, vascular hyperpermeability, and the metastasis of neoplasm will start. In the last decade, anti-VEGF antibodies have been developed as molecule target medicine. Especially bevacizumab which is an anti-
VEGF monoclonal antibody that binds to VEGF-A in VEGF and inhibits VEGF-A from binding to the receptors (VEGFR-1, VEGFR-2 and neurophilin 1). Bevacizumab is used with a combination of other anticancer drugs for treatment of non-small cell lung cancer besides squamous cell carcinoma (8). Squamous cell carcinoma is a contraindication for bevacizumab because of the side-effect of bleeding in the air way. Antiangiogenic agents can also transiently normalize the abnormal structure and function of tumor vasculature to make it more efficient for oxygen and drug delivery (9). VEGF was also expressed on alveolar epithelium, vascular endothelium and alveolar macrophages in normal and ARDS human lung tissues (10). The VEGF-C expression rate in cancer specimens was higher than in epithelial tissues or lymph nodes (11).

The present study showed higher staining scores of both VEGF and $\alpha$ SMA in adenocarcinoma compared with squamous cell carcinomas, particularly in differentiated tumor cells in lung cancers. Although there was no significant correlation of any score of VEGF, CD31 or $\alpha$ SMA to the prognoses, in 42 patients of high CD31 score, five-year survival rate of patients with lung cancer showing mature tumor vessels (high $\alpha$ SMA score) was significantly better than that of patients with immature tumor vessels (low $\alpha$ SMA score).

Higher VEGF staining score of adenocarcinomas in the present study is consistent with previous reports $(7,12,13)$. VEGF expression was significantly correlated with the density of tumor blood vessels, FDG uptake, TNM stage, tumor differentiation and lymph-node status $(7,14,15)$. VEGF expression was reported to be an independent prognostic factor for NSCLC (15). In this study, the five-year survival rate $(82 \%)$ of patients with high VEGF score tended to be better than that $(73 \%)$ of patients with low VEGF score, but there were no significant differences $(p=0.094)$. Although the present study did not prove the prognostic value of VEGF expression in lung cancer, other papers also reported that VEGF expression did not correlate with the survival of breast cancer patients (16), of oral squamous cell carcinoma (17), of cervical carcinomas (18) and of esophageal squamous cell carcinoma (19).

Normal vessels are stable, maturation-factors predominant and covered with support cells preventing leakage; tumor vessels are unstable, growth factors predominant, and are not covered with support cells resulting in increased leakage (20, 21). $\alpha$ SMA has proven to be a reliable maker for identifying vascular pericyte/smooth muscle (22). The aSMA staining score of adenocarcinomas was significantly higher than that of squamous cell carcinomas. Squamous cell carcinoma may have immature vessels and be likely to explode after treatment with bevacizumab. Lee et al. (23) proposed $\alpha$ SMA can be a promising prognostic biomarker and therapeutic target for metastatic lung adenocarcinoma. In the present study, five-year survival rate of patients with high $\alpha \mathrm{SMA}$ 
score tended to be better than that of patients with low $\alpha$ SMA score, although there was no significant difference ( $p=0.0936$ ). It is noticeable that higher $\alpha$ SMA staining score was demonstrated in differentiated lung cancers, which showed favorable prognosis. Furthermore, in lung cancers of high CD31 score, the five-year survival rate of patients with lung cancers consisting of mature vessels (high $\alpha$ SMA score) was significantly better than that of patients with cancers comprising immature vessels (low $\alpha$ SMA score). Greenberg et al. (24) reported a role for VEGF as a negative regulator of pericyte function and vessel maturation in vitro and in an animal study. However, we do not have enough molecular information on the roles of VEGF in maturation of blood vessels. The present study suggests that VEGF can be a positive regulator of pericyte as well as positive regulator of angiogenesis, which results in a favorable outcome in the differentiated lung cancer. Thus, treatment with bevacizumab does not necessarily bring a favorable effect on differentiated lung cancer. Further study is needed to clarify the exact roles of VEGF in lung cancer.

The less the cellular differentiation was, the lower VEGF and $\alpha$ SMA staining scores were. It means that well or moderately differentiated lung cancer might be treated with anti-VEGF antibodies, such as bevacizumab, and that poorly or undifferentiated lung cancer have immature vessels which are not covered by pericytes or smooth muscle.

\section{Conclusion}

The present study showed that not number of tumor vessels but maturation of tumor vessels demonstrated by $\alpha$ SMA is a prognostic factor of patients with lung cancer increased angiogenesis, suggesting that VEGF may not only stimulate proliferation of endothelial cells but also maturation of tumor vessels in differentiated lung cancers.

\section{Conflicts of Interest}

The Authors have declared no conflicts of interest.

\section{Acknowledgements}

This study was supported partly by a Grant-in-Aid for Scientific Research from the Ministry of Education, Culture, Sports, Science and Technology, Japan (Grant number: 16K10694) and by 2017 Grant-in-Aid of the Magnetic Health Science Foundation, Japan.

\section{References}

1. Ferrara N, Gerber HP and LeCouter J: The biology of VEGF and its receptors. Nat Med 9: 669-676, 2013.

2. Chen P, Zhu J, Liu DY, Li HY, Xu N and Hou M: Overexpression of survivin and VEGF in small-cell lung cancer may predict the poorer prognosis. Med Oncol 31(1): e775, 2014.
3 Chen W, He D, Li Z, Zhang X, Pan D and Chen G: Overexpression of vascular endothelial growth factor indicates poor outcomes of glioma: a systematic review and meta-analysis. Int J Clin Exp Med 8: 8709-8719, 2015.

4 Weng WC, Lin KH, Wu PY, Ho YH, Liu YL, Wang BJ, Chen CC, Lin YC, Liao YF, Lee WT, Hsu WM and Lee H: VEGF expression correlates with neuronal differentiation and predicts a favorable prognosis in patients with neuroblastoma. Sci Rep 7(1): e11212, 2017.

5 International Union Against Cancer: TNM classification of malignant tumours. 8th ed. New Jersey, John Wiley \& Sons, Inc. 2017.

6 Fukuoka J, Hofer MD, Hori T, Tanaka T, Ishizawa S, Nomoto $\mathrm{K}$, Saito M, Uemura T and Chirieac LR: Spiral array: a new high-throughput technology covers tissue heterogeneity. Arch Pathol Lab Med 136: 1377-1384, 2012.

7 Saijo Y, Furumoto H, Yoshida K, Nishimura M and Irahara M: Clinical Significance of vascular endothelial growth factor expression and microvessel density in invasive cervical cancer. J Med Invest 62: 154-160, 2015.

8 Sandler A, Gray R, Perry MC, Brahmer J, Schiller JH, Dowlati A, Lilenbaum R and Johnson DH: Paclitaxel-carboplatin alone or with bevacizumab for non-small-cell lung cancer. $\mathrm{N}$ Engl $\mathrm{J}$ Med 355: 2542-2550, 2006.

9 Jain RK: Normalization of tumor vasculature: an emerging concept in antiangiogenic therapy. Science 307: 58-62, 2005.

10 Medford AR, Douglas SK, Godinho SI, Uppington KM, Armstrong L, Gillespie KM, van Zyl B, Tetley TD, Ibrahim NB and Millar AB: Vascular Endothelial Growth Factor (VEGF) isoform expression and activity in human and murine lung injury. Respir Res 10: e27, 2009.

11 Wu QW, She HQ, Liang J, Huang YF, Yang QM, Yang QL and Zhang ZM: Expression and clinical significance of extracellular matrix protein 1 and vascular endothelial growth factor-C in lymphatic metastasis of human breast cancer. BMC Cancer 12: e47, 2012.

12 Bonnesen B, Pappot H, Holmstav J and Skov BG: Vascular endothelial growth factor A and vascular endothelial growth factor receptor 2 expression in non-small cell lung cancer patients: relation to prognosis. Lung Cancer 66: 314-318, 2009.

13 Guo J, Higashi K, Ueda Y, Ishigaki Y, Sakuma T, Oguchi M, Takegami T, Ohta Y, Zhang L, Xu K, Nishida H and Tonami H: VEGF-A and its isoform VEGF121 mRNA expression measured by quantitative real-time RT-PCR: correlation with F-18 FDG uptake and aggressiveness of lung adenocarcinoma: preliminary study. Ann Nucl Med 25: 29-36, 2011.

14 Guo J, Higashi K, Ueda Y, Oguchi M, Takegami T, Toga H, Sakuma T, Yokota H, Katsuda S, Tonami H and Yamamoto I: Microvessel density: correlation with 18F-FDG uptake and prognostic impact in lung adenocarcinomas. J Nucl Med 47: 419-425, 2006.

15 Lin Q, Guo L, Lin G, Chen Z, Chen T, Lin J, Zhang B and Gu $\mathrm{X}$ : Clinical and prognostic significance of OPN and VEGF expression in patients with non-small-cell lung cancer. Cancer Epidemiol 39: 539-544, 2015.

16 Chen Z, Xu S, Xu W, Huang J, Zhang GU, Lei L, Shao X and Wang X: Expression of cluster of differentiation 34 and vascular endothelial growth factor in breast cancer, and their prognostic significance. Oncol Lett 10: 723-729, 2015. 
17 Patil BR, Bhat K, Somannavar P, Hosmani J, Kotrashetti V and Nayak R: Comparison of immunohistochemical expression of vascular endothelial growth factor and CD105 in oral squamous cell carcinoa: Its correlation with prognosis. J Cancer Res Ther 14(2): 421-427, 2018.

18 Rahmani AH, Babiker AY, Alsahli MA, Almatroodi SA and Husain NEOS: Prognostic significance of vascular endothelial growth factor (VEGF) and Her-2 protein in the genesis of cervical carcinoma. Open Access Maced J Med Sci 6(2): 263268,2018

19 Luz CCF, Noguti J, Araújo L, Simão Gomes T, Mara G, Silva MS and Artigiani Neto R: Expression of VEGF and Cox-2 in patients with esophageal squamous cell carcinoma. Asian Pac J Cancer Prev 19: 171-177, 2018.

20 Jain RK: Molecular regulation of vessel maturation. Nat Med 9: 685-693, 2003.

21 Carmeliet P: Angiogenesis in health and disease. Nat Med 9: 653-660, 2003.
22 Chaponnier C and Gabbiani G: Pathological situations characterized by altered actin isoform expression. J Pathol 204: 386-395, 2004.

23 Lee HW, Park YM, Lee SJ, Cho HJ, Kim DH, Lee JI, Kang MS, Seol HJ, Shim YM, Nam DH, Kim HH and Joo KM: Alphasmooth muscle actin (ACTA2) is required for metastatic potential of human lung adenocarcinoma. Clin Cancer Res 19: 5879-5889, 2013.

24 Greenberg JI, Shields DJ, Barillas SG, Acevedo LM, Murphy E, Huang J, Scheppke L, Stockmann C, Johnson RS, Angle N and Cheresh DA: A role for VEGF as a negative regulator of pericyte function and vessel maturation. Nature 456(7223): 809-813, 2008.

Received May 20, 2018

Revised June 9, 2018

Accepted June 12, 2018 